\title{
The ryanodine receptor as a sensor for cellular environments in muscles
}

Takuya Kobayashi*, Nagomi Kurebayashi, and Takashi Murayama*

Department of Cellular and Molecular Pharmacology, Juntendo University Graduate School of Medicine, Tokyo, Japan

* Corresponding author: Takuya Kobayashi (tkoba@juntendo.ac.jp); Takashi Murayama (takashim@juntendo.ac.jp).

\begin{abstract}
The ryanodine receptor (RyR) is a $\mathrm{Ca}^{2+}$ release channel in the sarcoplasmic reticulum of skeletal and cardiac muscles and plays a key role in excitation-contraction coupling. The activity of the RyR is regulated by many intracellular factors such as divalent cations $\left(\mathrm{Ca}^{2+}\right.$ and $\left.\mathrm{Mg}^{2+}\right)$, nucleotides, associated proteins, and reactive oxygen species. Since these intracellular factors change depending on the condition of the muscle, e.g., exercise, fatigue, or disease states, the RyR channel activity will be altered accordingly. In this review, we describe how the RyR channel is regulated under various conditions and discuss the possibility that the RyR acts as a sensor for change in the cellular environment of muscles.
\end{abstract}

Keywords: Ryanodine receptor; skeletal muscle; cardiac muscle; exercise and injury; heart function; diet

\section{Introduction}

Skeletal and cardiac muscles are essential organs for the maintenance of life, which embodies all activities, such as walking, eating, and creating. Skeletal muscles are required to perform flexible and complex movements, generate and maintain force, and respond rapidly to different conditions, while the heart muscle sustains and regulates the heartbeat according to physical activity. In addition, during human physical activities, muscles are subjected to high-loads and fatigue and various external stimuli, such as injury, stress, and excitement. These external stimuli cause intricate changes in the intracellular environment of muscle cells. If a control unit in muscle can sense the intracellular environment, the muscle can immediately respond to various stimuli without waiting for commands from the brain.

The contractile activity of skeletal and cardiac muscles is induced by a series of events, including action potential changes, $\mathrm{Ca}^{2+}$ release from the sarcoplasmic reticulum $(\mathrm{SR})$, and contractile force generation. The ryanodine receptor (RyR) is a $\mathrm{Ca}^{2+}$ release channel in the SR. In skeletal muscle, the type 1 RyR (RyR1) interacts with the dihydropyridine receptor (DHPR or Cav1.1), an L-type $\mathrm{Ca}^{2+}$ channel in the transverse tubule (T-tubule). As a result, channel opening is triggered by a conformational change in the DHPR after depolarization of the T-tubule (referred to as depolarization-induced $\mathrm{Ca}^{2+}$ release, DICR) [1][2][3]. In cardiac muscle, the type $2 \mathrm{RyR}(\mathrm{RyR} 2)$ is opened by the binding of $\mathrm{Ca}^{2+}$ that is introduced from the extracellular space through the DHPR (Cav1.2) (referred to as $\mathrm{Ca}^{2+}$-induced $\mathrm{Ca}^{2+}$ release, CICR). However, in cardiac muscle, a direct interaction between the RyR2 and DHPR is lacking. The opening of RyR channels releases massive $\mathrm{Ca}^{2+}$ from the SR. Thus, the intracellular $\mathrm{Ca}^{2+}$ concentration rapidly increases from $50 \mathrm{nmol} / \mathrm{L}$ during the resting state to $10-20 \mu \mathrm{mol} / \mathrm{L}$ as maximum peak in twitch contraction [4][5][6]. A structural change in tropomyosin on the thin muscle filament is caused by $\mathrm{Ca}^{2+}$ binding to troponin $\mathrm{C}$, and this change facilitates the interaction between myosin and actin, resulting in muscle contraction [7][8]. Thus, the 
RyR is the most important element in excitation-contraction coupling and a central component of the myocyte system.

The RyR is a huge (>2 MDa) protein complex, which is composed of four $550 \mathrm{kDa}$ subunits. The RyR forms six-transmembrane P-type channels at the C-terminus and a large N-terminal cytoplasmic region which covers $70 \%$ of the entire molecule [9]. Recent cryo-EM studies of RyRs revealed a complex structure with over 15 domains [10][11][12]. The transmembrane S1, S3 and S5 helices penetrate the SR membrane from the cytosolic side to the luminal side, whereas the S2, S4 and S6 helices penetrate the membrane in the opposite direction. The $\mathrm{S} 6$ helix forms a pore for $\mathrm{Ca}^{2+}$ ions. The S2-S3 domain, which is the inter domain between S2 and S3 helices on the cytosolic side, is thought to be involved in regulation of channel opening. The S4-S5 linker is a short helix that runs parallel to the SR membrane between the S4 and S5 helices and participates as a stopper against the movement of S6 helix. The C-terminal domain (CTD) forms a part of $\mathrm{Ca}^{2+}$ and nucleotide binding sites at the C-terminal side of the S6 helix. The C-terminal domain is involved in channel gating and comprises the channel core. The large $\mathrm{N}$-terminal cytoplasmic region which is unique to the RyR family contains multiple domains, including the NTD, SPRY1, P1, SPRY2, SPRY3, Handle, HD1, P2, HD2, and Central domains. Since many disease-linked point mutations have been identified in RyR cytoplasmic domains, this region is thought to be involved in the regulation of channel activity [13].

In this review, we will first describe the regulatory factors, such as small molecules, proteins, and modifications that affect RyR channel activity from a biochemical perspective (Table 1). Next, we will discuss changes in these regulatory factors in muscles during daily activities and crisis situations to understand macroscopic biological phenomena from a molecular perspective. In this way, we will demonstrate that RyRs play a major role in human activity and life support (Fig. 1) and discuss RyRs as intracellular environmental sensors for various signals.

\section{Factors affecting RyR function}

\section{1. $\mathrm{Ca}^{2+}$}

$\mathrm{Ca}^{2+}$ is a primary ligand for RyRs that induces channel opening. The channel activity increases at micromolar concentrations of $\mathrm{Ca}^{2+}$ in all $\mathrm{RyR}$ subtypes. However, $\mathrm{Ca}^{2+}$ does not only open the channel, it leads to channel closing when higher concentrations are reached (sub-millimolar or more) [14][15]. The biphasic $\mathrm{Ca}^{2+}$ dependence is explained by the presence of two distinct $\mathrm{Ca}^{2+-b i n d i n g}$ sites: a high-affinity site involved in opening the RyR channel and a low-affinity site for inactivation [16][17]. The $\mathrm{Ca}^{2+}$ concentration for the inactivation differs between RyR1 and RyR2; the activity of RyR1 is inhibited by sub-millimolar $\mathrm{Ca}^{2+}$, however, millimolar or more $\mathrm{Ca}^{2+}$ level are required for RyR2 the inhibition. The high-affinity $\mathrm{Ca}^{2+-b i n d i n g}$ site for channel activation is located in the interface between the Central domain and CTD [10].

\section{2. $\mathrm{Mg}^{2+}$ and adenine nucleotides}

$\mathrm{Mg}^{2+}$ has an inhibitory effect on the RyR channels [17-19]. $\mathrm{Mg}^{2+}$ acts as a competitive inhibitor for the activating, high-affinity $\mathrm{Ca}^{2+}$-binding site and an agonist for the inactivating, low-affinity $\mathrm{Ca}^{2+}$ site [20][21]. The $\mathrm{EC}_{50}$ of $\mathrm{Mg}^{2+}$ for the inactivating $\mathrm{Ca}^{2+}$-binding site is similar to that of $\mathrm{Ca}^{2+}$, whereas the $\mathrm{EC}_{50}$ is lower than that of $\mathrm{Ca}^{2+}$ for the activating $\mathrm{Ca}^{2+}$ site [22] [23]. Although $\mathrm{Mg}^{2+}$ is predicted to bind to these $\mathrm{Ca}^{2+}$-binding sites, there is no structural evidence for $\mathrm{Mg}^{2+}$ binding thus far.

Adenine nucleotides (ATP, ADP and AMP) increase the RyR activity [18][19]. The rank order of activation is ATP $>A D P>A M P$ : The EC 50 of ADP to RyR2 is one order of magnitude higher than that of ATP [24]. The concentration of ATP, ADP and AMP at resting skeletal muscle is $8.5 \mathrm{mmol} / \mathrm{L}, 0.008 \mathrm{mmol} / \mathrm{L}$ and $0.007 \mu \mathrm{mol} / \mathrm{L}$, whereas those 
after exercise is $8.5 \mathrm{mmol} / \mathrm{L}, 0.15 \mathrm{mmol} / \mathrm{L}$ and $2.7 \mu \mathrm{mol} / \mathrm{L}$, respectively [25]. RyR is predicted to have two ATP-binding sites in one protomer [26], but structural studies have revealed that only one ATP is identified at the interface between Central, S6 and CTD which is near the $\mathrm{Ca}^{2+}$ binding site [10]. Because other adenine nucleotides can also bind to the site, displacement of ATP by ADP might occur when ADP concentration is increased. In consequence, an increase in ADP concentration causes a reduction of $\mathrm{Ca}^{2+}$ release.

The change in concentrations of the factors described above is mainly involved in high-load exercises. We will discuss these changes further in the exercise and fatigue section of this review.

\subsection{SR luminal $\mathrm{Ca}^{2+}$ and calsequestrin}

Single-channel recording experiments showed that the activity of RyRs increased when the concentration of luminal $\mathrm{Ca}^{2+}$ increased above $1 \mathrm{mmol} / \mathrm{L}$ in the SR, whereas trypsin treatment of the luminal side of the SR membrane decreased RyR activity after $\mathrm{Ca}^{2+}$ concentrations increased [27]. Therefore, it was proposed that RyRs have at least two types of luminal $\mathrm{Ca}^{2+}$ sensor sites in the SR lumen: one for activation and one for inhibition. A recent study of RyR2 showed that the E4872A mutation abolished luminal $\mathrm{Ca}^{2+}$ activation, suggesting that this site may be part of the luminal $\mathrm{Ca}^{2+}$ sensor [28]. Some studies have discussed the mechanism of sensing the luminal $\mathrm{Ca}^{2+}$ concentrations in relation to ATP. Single-channel recording showed that the affinity of the RyR for ATP decreased when the concentration of luminal $\mathrm{Ca}^{2+}$ was less than $1 \mathrm{mM}$, and the effect of ATP on RyR activation increased when the concentration of luminal $\mathrm{Ca}^{2+}$ was 8-35 $\mathrm{mmol} / \mathrm{L}$ [29]. $\mathrm{Ca}^{2+}$ release through RyR2 occurs spontaneously when a high luminal $\mathrm{Ca}^{2+}$ concentration is present [30][28].

Calsequestrin is a low affinity, high capacity $\mathrm{Ca}^{2+}$-binding protein in the SR and is thought to act as a $\mathrm{Ca}^{2+}$ buffer [31][32][33]. In addition, calsequestrin inhibits RyR channel activity [34][35]. It has been reported that the inhibitory effect of calsequestrin is induced when the luminal $\mathrm{Ca}^{2+}$ concentration drops below $0.1 \mathrm{mmol} / \mathrm{L}$ [36][37]. Moreover, calsequestrin can bind to junctin and triadin, which are SR membrane proteins that promote $\mathrm{Ca}^{2+}$ release though the RyR [38][37].

In an imaging study of the flexor digitorum brevis (FDB) muscle, the concentration of luminal $\mathrm{Ca}^{2+}$ was $0.4 \mathrm{mmol} / \mathrm{L}$ at rest and fell to $0.08 \mathrm{mmol} / \mathrm{L}$ after tetanic stimulation at $50 \mathrm{~Hz}$. This result indicated that approximately $88 \%$ of the luminal $\mathrm{Ca}^{2+}$ was released during tetanic contractions [39].

The change in concentration of these factors is mainly involved in high-load exercises. We will discuss them in the exercise and fatigue section of this review.

\section{4. $p H$}

Similar to many proteins in the cell, $\mathrm{pH}$ regulates the activity of RyRs [40]. The maximum activity of RyR1 is exhibited at $\mathrm{pH} 8.0$, and sensitivity to $\mathrm{Ca}^{2+}$ decreases with decreasing $\mathrm{pH}$ [33]. The cytosolic $\mathrm{pH}$ is usually 7.0 in resting muscle, and exercise induces an acidic shift of $\mathrm{pH}$ to 6.7 [25][41]. The change in this factor is mainly involved in high-load exercises. We will discuss this in the exercise and fatigue section of this review.

\subsection{Dihydropyridine receptor (DHPR)}

In skeletal muscle, RyR1 is under the control of the DHPR. Therefore, abnormalities in the DHPR are directly related to RyR1 function [42][43][44]. Amino acid mutations in the DHPR cause diseases such as malignant hyperthermia and myopathy [45]. In addition, drugs that cause depolarization of cell membranes, such as depolarizing muscle relaxants, have been implicated in myopathy. Malignant hyperthermia can be 
induced not only by inhalational anesthetics but also by depolarizing muscle relaxants, e.g., suxamethonium [46]. This is caused by $\mathrm{Ca}^{2+}$ release from RyR1 after activation of the DHPR by depolarization. Furthermore, changes in blood potassium ion concentrations may also alter the cellular membrane potential and affect the excitation-contraction coupling and $\mathrm{Ca}^{2+}$ release from RyR1.

\subsection{FKBP12}

FKBP12 is a protein that binds to the immunosuppressive agent FK506, which is used in patients with organ transplants or autoimmune diseases. FKBP12 binds to RyRs [47] and modulates their activity [48][49][50]. FKBP12.6 is an isoform of FKBP12 with a different molecular weight and is expressed abundantly in the heart. RyR1 and RyR2 tightly bind to FKBP12 and FKBP12.6, respectively [48][50][49]. Because of the tight binding between the RyRs and FKBP12/FKBP12.6 (KD $\sim \mathrm{nmol} / \mathrm{L})$, the RyR channel is thought to form an octamer (4 RyR subunits and 4 FKBP12/12.6 proteins). FKBP12 has an inhibitory effect on RyR1 activity [51]. In addition, FKBP12 may promote binding between RyR1 and the DHPR [52]. Thus, RyR1 activity is constantly suppressed by FKBP12. Similar effects were proposed for RyR2 and FKBP12.6 [53]. However, it has been reported that FKBP12 has no inhibitory effect on the RyR in the aorta [54]. The changes in these factors are mainly involved in exercise, oxidative stress and ischemia/reperfusion injury. We will discuss them in the exercise and fatigue, skeletal muscle crisis and modulation of heart function in health and disease section of this review.

\subsection{Calmodulin}

Both RyR1 and RyR2 can bind to calmodulin [55]. Calmodulin has biphasic effects on RyR1 depending on whether $\mathrm{Ca}^{2+}$ is bound to the protein. Apo-calmodulin $\left(\mathrm{Ca}^{2+}\right.$ free) activates the RyR1 channel, whereas $\mathrm{Ca}^{2+}$-calmodulin inhibits it [56] [57] [58]. $\mathrm{Ca}^{2+}$-calmodulin inhibits RyR2 activity, but apo-calmodulin has no effect [59]. The complex structures of the RyR and calmodulin have been determined, and it was shown that calmodulin binds to the Central domain of the RyR [60][61]. S100A1, a 21 kDa $\mathrm{Ca}^{2+}$-binding protein, can also bind to the calmodulin binding site of the RyR, and it has been reported that the peak of $\mathrm{Ca}^{2+}$ transients is reduced in skeletal muscle lacking this protein [62]. The change in concentration of this factor is mainly involved in tachycardia. We will discuss this change in the modulation of heart function in health and disease section of this review.

\subsection{Phosphorylation}

Phosphorylation is an important modification in intracellular signal transduction. It has been demonstrated that the RyR is phosphorylated [63]. Although the mechanism is not fully understood, phosphorylation may alter the activation of the RyR that is mediated by ATP [64]. In RyR2, there are currently three serine residues that are targets for phosphorylation (S2030, S2808, and S2814). These amino acids are thought to be phosphorylated by protein kinase A (PKA), protein kinase $\mathrm{C}$ (PKC) or $\mathrm{Ca}^{2+} /$ calmodulin-dependent protein kinase II (CaMKII) [65]. The change in this factor is mainly involved in exercise and excitement, ischemia/reperfusion injury, catecholaminergic polymorphic ventricular tachycardia (CPVT) and diabetes. We will discuss these factors in the modulation of heart function in health and disease and diet, diabetes section of this review.

\subsection{S-nitrosylation and oxidation}

There are thiols in the RyR that undergo oxidative modifications [66], and the channel activity increases when these thiol groups undergo S-nitrosylation or S-glutathionylation. In experiments using various nitric oxide (NO) donors, some 
donors enhanced activity, while others showed an inhibitory tendency [67]. These results suggest that there may be multiple target cysteine residues that undergo oxidative modification [68]. The RyR1 Cys3635 residue has been identified as an S-nitrosylation target [69]. It has been reported that thiol modifications promote not only the activity of the RyR itself but also the dissociation of FKBP12 and $\mathrm{Ca}^{2+}$-bound calmodulin [70], thereby leading to an increase in channel activity by relieving FKBP12-mediated suppression (Fig. 1A).

It is also known that RyRs can be oxidized by reactive oxygen species (ROS), especially hydroxyl radicals $(-\mathrm{OH})$, which dissociate calmodulin from RyR2 and release the receptor from calmodulin-induced inhibition [71][72]. Hydroxyl radicals are produced from $\mathrm{H}_{2} \mathrm{O}_{2}$ by the Fenton reaction: therefore, the concentration of $-\mathrm{OH}$ is closely related to that of $\mathrm{H}_{2} \mathrm{O}_{2} . \mathrm{H}_{2} \mathrm{O}_{2}$ is generated in mitochondria and permeates the cell membrane easily. The production of $\mathrm{H}_{2} \mathrm{O}_{2}$ in normal tissues has been reported to be 100-400 $\mathrm{pmol} / \mathrm{min} / \mathrm{mg}$ [73][74][75][76]. $\mathrm{H}_{2} \mathrm{O}_{2}$-induced RyR activation occurs at concentrations below $1 \mathrm{mM}$, and higher concentrations cause inhibition. The inhibitory effect is abrogated by thiol modification [77], and it has been reported that S-nitrosylation protects the RyR from oxidation by ROS [78]. Oxidative modifications occur not only on the RyR but also on FKBP12.6, which causes dissociation from RyR2 and relieves the receptor from FKBP12.6-mediated suppression [79][80]. Furthermore, treatment of RyR2 with dithiothreitol altered the activity of RyR2 in response to luminal $\mathrm{Ca}^{2+}$ concentration. Therefore, it is possible that cytoplasmic redox status affects the luminal $\mathrm{Ca}^{2+}$ sensor as well [81]. The changes in these factors are mainly involved in high load-bearing work, muscle injury, heat stress, and individuals who consume a high-fat diet. We will discuss these changes in the exercise and fatigue, skeletal muscle crisis, modulation of heart function in health and disease and diet, diabetes section of this review.

\subsection{NADH/NAD}

Nicotinamide adenine dinucleotide (NADH) is a cofactor in redox reactions, and the ratio of NADH to NAD changes in cells during energy metabolism. NADH and NAD have been shown to increase RyR1 activity [82]. The $\mathrm{NADH}$ was reported as 0.1-0.5 mmol/L in resting skeletal muscle [83][84], and the ratio of NADH/NAD was 0.002-0.003 [85][86]. The EC 50 of NADH and NAD for activation of RyR1 was shown to be $0.23 \mathrm{mmol} / \mathrm{L}$ and $0.31 \mathrm{mmol} / \mathrm{L}$, respectively [82]. For RyR2, activity is decreased by $\mathrm{NADH}$, and NAD counteracts the effect of NADH and restores the the RyR2 channel activity [87]. Because the effects of NADH and NAD are opposite to each other, the ratio of NADH/NAD is a key factor in heart function. The ratio of NADH/NAD was reported to be 0.04-0.05 in heart muscle [88][89][90]. The change in this factor is mainly involved in myocardial metabolism. We will discuss this change in the modulation of heart function in health section of this review.

\subsection{Acyl-CoA}

Acyl-CoA [91] and acly-carnitine [92], which are metabolic intermediates of lipid metabolism, have been shown to directly increase RyR activity. In particular, palmitoyl-CoA is thought to reduce RyR inhibition mediated by $\mathrm{Mg}^{2+}$ [93]. Furthermore, acyl-CoA and acyl-CoA-binding protein may interact with FKBPs to regulate RyR activity [94]. Changes in these factors are mainly involved in individuals who consume a high-fat diet. We will discuss these factors further in the diet, diabetes section of this review.

\subsection{Lipid}

Several lipids are known to affect the activity of RyRs, but the majority of these are not biological substances and are not expected to directly interact with RyRs. Several 
sphingolipids have been shown to inhibit RyR1 activity in physiological situations [95]. However, it is not clear whether they actually interact in vivo.

\section{Changes in regulatory factors in muscle under various situations}

\subsection{Exercise and fatigue}

Exercise and high load-bearing work cause various changes in skeletal muscle. In particular, during eccentric contraction, the expression of the NADPH oxidase (Nox)4, which produces superoxide from oxygen is increased and substantial ROS are generated [96][97]. ROS scavengers abolish the exercise-induced increase in $\mathrm{Ca}^{2+}$ release in skeletal muscle [98]. Although these studies on ROS generation were not always directly related to RyRs, ROS production was shown to correlate with increased $\mathrm{Ca}^{2+}$ release and muscle tension. It has also been reported that the binding of FKBP12 to RyRs in muscle is reduced by eccentric contraction [99], and as noted above, dissociation reduces FKBP12-mediated suppression of RyR activity (Fig. 1A). In most cases, exercise increases RyR activity, which in turn increases muscle tension (Fig. 1B).

When high-frequency stimulation is sustained, muscle tension gradually declines and the muscle falls into a state of fatigue. Under these conditions, a large amount of ATP is consumed by myosin and sarcoendoplasmic reticulum calcium ATPase (SERCA) in the muscle. Studies measuring ATP concentrations in creatine-kinase inhibited muscle fibers have shown that the ATP concentration in resting muscle was estimated to at 6-8 $\mathrm{mmol} / \mathrm{L}$, but decreased to approximately $3 \mathrm{mmol} / \mathrm{L}$ during contraction and $1.7 \mathrm{mmol} / \mathrm{L}$ when consumption was high [100]. Experiments using skinned fiber have shown that contractility decreased when the ATP concentration fell below $2 \mathrm{mmol} / \mathrm{L}$ [101]. The concentration of $\mathrm{Mg}^{2+}$, which was released from MgATP also increased with consumption of ATP [102]. However, normal exercise does not substantially reduce the ATP concentration in muscles [103][25][104], but rather a large amount of ADP is generated as a by-product [104]. ADP does not maintain RyR activity as efficiently as ATP [24]. Therefore, the abundant increase in ADP may suppress channel activity induced by ATP. When high load-bearing exercise increases the ADP/ATP ratio, the impact of ADP may be enhanced.

The SR luminal $\mathrm{Ca}^{2+}$ concentration decreased from $1 \mathrm{mmol} / \mathrm{L}$ to $0.08 \mathrm{mmol} / \mathrm{L}$ after exercise and high load-bearing work in one study [39]. The RyR senses a reduction in luminal $\mathrm{Ca}^{2+}$ concentration and channel activity decreases. In addition, when luminal $\mathrm{Ca}^{2+}$ is depleted, calsequestrin binds to the RyR and suppresses its activity. Moreover, acidification of the muscle cytosol by exercise [25] causes suppression of RyR activity. Thus, high load-bearing work results in muscle fatigue that suppresses RyR activity (Fig. $1 C)$.

\subsection{Skeletal muscle crises}

Skeletal muscles are close to the body surface and are exposed to external environments. Therefore, strong pressure or blows can lead to muscle contusions. It is known that muscle injury increases the production of $\mathrm{H}_{2} \mathrm{O}_{2}$ [105] and various other $\mathrm{ROS}$ [106][107]. Although ROS, including $\mathrm{H}_{2} \mathrm{O}_{2}$ are known to increase RyR activity, an increase in RyR activity is not generated in damaged muscle fibers during exercise because damaged fibers are unable to contract [106][107]. However, it has been shown that ROS can spread from the site of injury and affect other muscle fibers and tissues. In particular, $\mathrm{H}_{2} \mathrm{O}_{2}$ has a large impact because it can easily permeate the cell membrane. Excessive contraction of the surrounding fibers because of increased RyR activity may increase damage to the contusion site. It has been reported that cooling of the contusion site reduces ROS production [107]. Thus, preventing the increase in RyR activity after muscle injury may be an important aspect of early treatment. Other external stresses include heat stress, which is known to cause a transient increase in oxidation [108], increased mitochondrial ROS production [109], and increased expression of endothelial 
nitric oxide synthase (NOS) [110]. As in the case of muscle contusion, heat stress also leads to an increase in ROS production. In this case, $\mathrm{Ca}^{2+}$ release from RyRs is increased and ATP-dependent $\mathrm{Ca}^{2+}$ uptake by SERCA is enhanced, which may lead to fever, and subsequent heat stroke. In fact, it has been reported that mice with a malignant hyperthermia mutation in RyR1 displayed increased RyR activity and rapid fever after the induction of heat stress, with unfortunate feedback that enhanced mitochondrial ROS production, and resulted in sudden death [111].

Changes in redox state are commonly observed with stress. For example, restraint induced disuse is well known to cause atrophy, which increases $\mathrm{H}_{2} \mathrm{O}_{2}$ [112] and neuronal NOS [113][114]. Changes in redox state occur during hypoxia at high altitude. Under these conditions, an increase in oxidized proteins [115] and a decrease in FKBP12 accompanied by an increase in ROS and NO [116] has been reported. At high altitudes, muscle injury may be induced by intense contractions because the activity of RyR1 is already increased (Fig. 1D).

Aging must also be discussed as one of the crises coming to the muscle. Although many studies have been performed on aging and muscle atrophy, there are not many reports on factors that regulate RyR activity. However, it was demonstrated that calsequestrin increases with age [117]. Additionally, the coupling of the DHPR and RyR1 is also decreased with aging [118].

\subsection{Modulation of heart function in health and disease}

The heartbeat is formed by regular $\mathrm{Ca}^{2+}$ release from the RyR2 channel, which is controlled by an action potential. The rate of the heartbeat is usually $60-100$ beats per minute in humans, but it is known to be higher during exercise and psychological stress. When the sympathetic nervous system is stimulated by exercise or excitement, $\beta$-adrenergic signaling activates PKA in the myocardium and increases amplitude of cardiac action-potential-induced $\mathrm{Ca}^{2+}$ release from $\mathrm{RyR} 2$ by direct and indirect mechanisms. The factors that enhance RyR2 activity are elevation of SR luminal $\mathrm{Ca}^{2+}$, which results from an increase in $\mathrm{Ca}^{2+}$ influx via L-type $\mathrm{Ca}^{2+}$ channels and enhanced SERCA activity, and increased phosphorylation of RyR2 (S2030 and S2808) [119][120]. NO production is also increased under exercise and stress conditions. These factors all potentiate RyR2 activity and result in strong contractions [121][122].

Heart failure is a highly prevalent progressive cardiac disorder with high morbidity and mortality. It arises from various causes, including coronary artery disease leading to cardiac arrest, high blood pressure, atrial fibrillation, valvular heart disease, and cardiomyopathy. When the ejection force is reduced during heart failure, the heart is unable to sufficiently maintain blood flow to meet the oxygen demands of tissues. The sympathetic nervous system is activated in the early stage of heart failure, which accelerates phosphorylation of RyR2 by PKA. NO production is increased during heart failure [123]. It was reported that inducible NOS expression increased in failing cardiomyocytes [124]. In addition to the increase in NOS, an increase in Nox expression has also been reported during heart failure [125][126]. Nox is an enzyme involved in the generation of ROS [127][128], and ROS promotes RyR oxidation and contributes to increased channel activity. As noted above, phosphorylation, S-nitrosylation, and oxidation may contribute to the activation of RyR2. Moreover, it has been reported that FKBP12.6 dissociates from RyR2 as heart failure progresses [129][130], which likely contributes to increased RyR2 activity (Fig. 1E). The immediate activation of RyR2 by early compensatory mechanisms that involve these factors may restore cardiac function and physical safety.

The chronic activation of RyR2 has deleterious effects on cardiac function. The chronic and inordinate activation of RyR2 causes diastolic $\mathrm{Ca}^{2+}$ leakage from the SR and/or generation of $\mathrm{Ca}^{2+}$ waves. The former leads to contractile dysfunction and the latter causes arrhythmias. Elevated intracellular calcium levels activate CaMKII, which 
is also involved in the phosphorylation of RyRs. CaMKII was found to be increased in failing cardiomyocytes [131] and may be involved in the subsequent development of disease-related ventricular remodeling [132] or arrhythmia [133]. Therefore, excessive activation of RyR2 may lead to worsening of heart failure rather than improvement of cardiac function. Interestingly, introduction of calmodulin that had high binding affinity for RyR2 into animal models prevented progression to arrhythmia [134] and reduced the symptoms of CPVT [135]. These results indicate that it may be desirable to return to a moderate level of RyR2 activity in the heart after the emergency period has ended.

Similar to heart failure, impaired cardiac function caused by ischemia-reperfusion injury also promotes ROS and NO production, phosphorylation, and dissociation of FKBP12.6 from RyR2 [136]. Ischemia-reperfusion is defined as the restoration of coronary blood flow after an ischemic episode. This injury to the myocardium causes the reduction of ejection force, and the increased demand for oxygen in tissues is similar to that observed for intense exercise and heart failure. It has been reported that phosphorylation of S2814 by CaMKII is enhanced after ischemia-reperfusion [137]. Increased oxidation of RyR2 is a result of the increase in ROS generation in cardiomyocytes [138][139] (Fig. 1D and E). The influence of ROS reaches the cardiomyocytes that surround the injured myocytes. Furthermore, ROS produced from tissues other than heart tissue are also involved in RyR2 modulation. Strong oxidative stress responses occur after burns and include activation of RyR2 and leakage of calcium from the SR in cardiomyocytes, which leads to heart failure [140].

Heart failure has been shown to have a significant effect on skeletal muscle. Biopsies of skeletal muscle from patients with heart failure have shown that RyR1 binding to FKBP12 is reduced [141]. It has been reported that phosphorylation of the S2843 residue of RyR1 by PKA dissociates FKBP12 from the receptor, and phosphorylation and dissociation of FKBP12 were also observed in an animal model of heart failure [142].

\subsection{Diet, Diabetes}

RyRs may also be sensitive to the effects of diet. It has been shown that a high-fat diet enhances $\beta$-oxidation, which in turn enhances ROS generation in the mitochondria [143] and S-nitrosylation of RyR1, which increases RyR1 activity. Prolonged S-nitrosylation, however, leads to a state of sustained high $\mathrm{Ca}^{2+}$ concentration, which activates CaMKII and enhances RyR1 phosphorylation [144]. Since increased cytosolic levels of acyl-CoA and acyl-carnitine increase RyR1 activity [91][92][93], a high-fat diet also acts to increase RyR1 activity (Fig. 1F). Increased RyR1 activity in skeletal muscle leads to increased mobility; therefore, exercise after a high-fat meal is advantageous. In particular, swimming increased the activity of superoxide dismutase (SOD) and glutathione peroxidase (GSH-Px) in skeletal muscle [145], which may suppress excessive diet-induced activation of RyR1. A high-fat diet also affects the myocardium. Accumulation of palmitoyl-carnitine, a long-chain fatty ester of acyl-carnitine, has been shown to increase mitochondrial ROS production, RyR2 oxidation and S-nitrosylation and FKBP12.6 dissociation, which in turn may lead to increased $\mathrm{Ca}^{2+}$ spark frequency and development of tachycardia [146] (Fig. 1E).

Long-chain unsaturated fatty acids, such as eicosapentaenoic acid (EPA), docosahexaenoic acid (DHA), and oleic acid, in contrast, have been shown to decrease the activity of RyR2 [147][148]. Although the mechanism is not fully understood, DHA has been shown to enhance the stability of RyR2-FKBP12.6 binding through its oxidized neuroprostane by-product (NeuroP) [148]. Furthermore, DHA has been found to reduce RyR2 mRNA expression [149].

It has been noted that $\mathrm{Ca}^{2+}$ release is abnormal in diabetes mellitus [150][151]. Decreased glucose utilization and increased $\beta$-oxidation increase ROS, as does the consumption of a high-fat diet. The production of $\mathrm{H}_{2} \mathrm{O}_{2}$ is increased 1.5 times in 
hyperinsulinemic premenopausal women [152]. When ROS scavengers and CaMKII inhibitors were added to the myocardium from diabetic models, the peak $\mathrm{Ca}^{2+}$ transients were normalized and spontaneous $\mathrm{Ca}^{2+}$ release was suppressed [151][153]. It is also known that phosphorylation occurs to a high degree in diabetic cardiac RyRs [154][150]. In particular, it has been shown that S2809 is phosphorylated [155].

\subsection{Figure and table}

A Normal
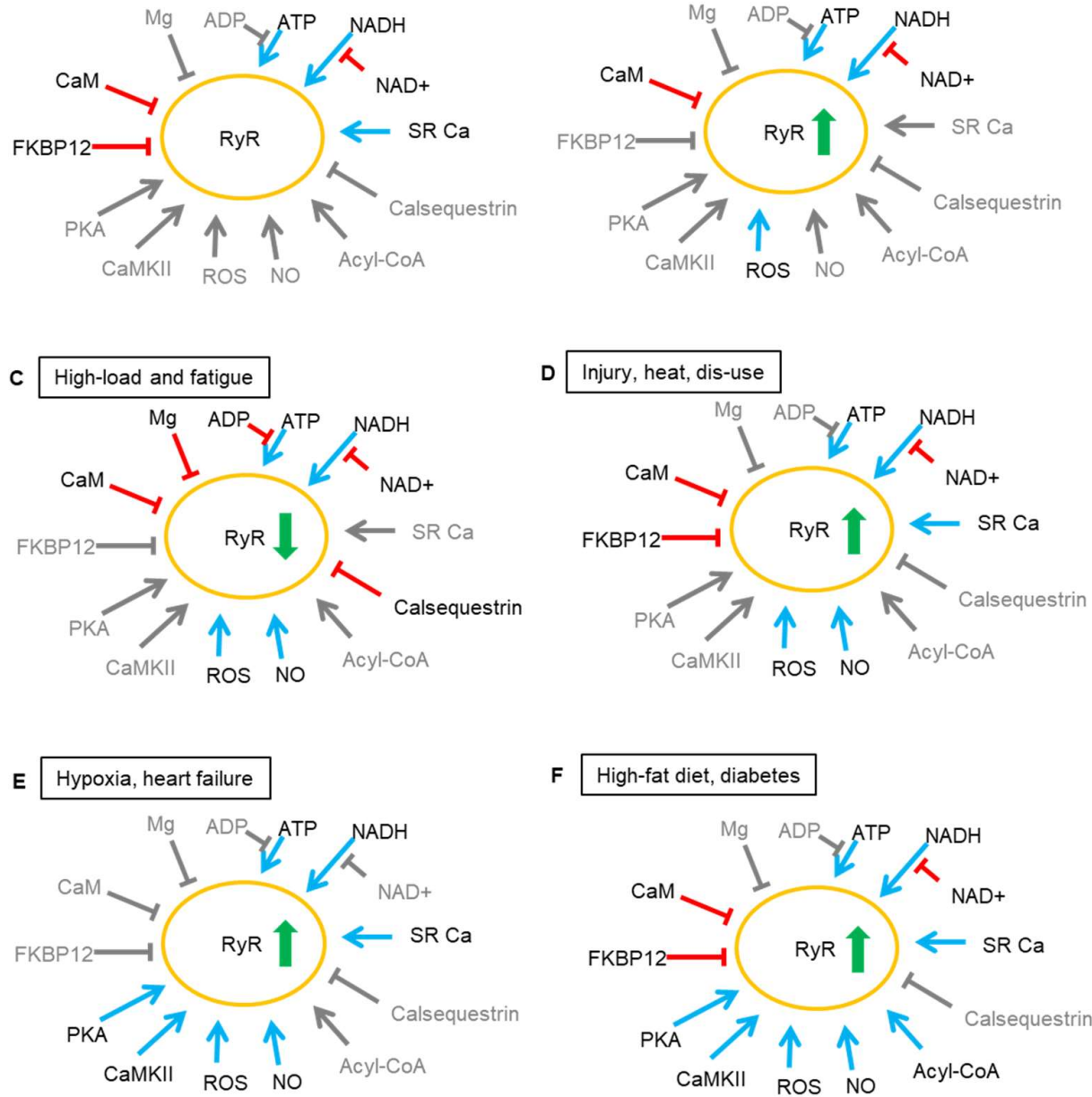

F High-fat diet, diabetes

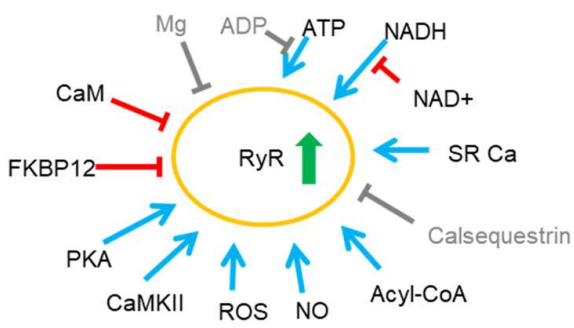

Fig. 1. Schematic representation of changes in ryanodine receptor (RyR) activity induced by intracellular factors under multiple conditions. (A) Resting condition. (B) Training with eccentric contraction. (C) High-load bearing work and fatigue. (D) Destructive situations caused by injury, heat stress, and dis-use. (E) Hypoxic response and heart failure. (F) Metabolic activation or abnormality.

Table 1. The effects of changes in intracellular factors on the activity of the ryanodine receptor in muscle.

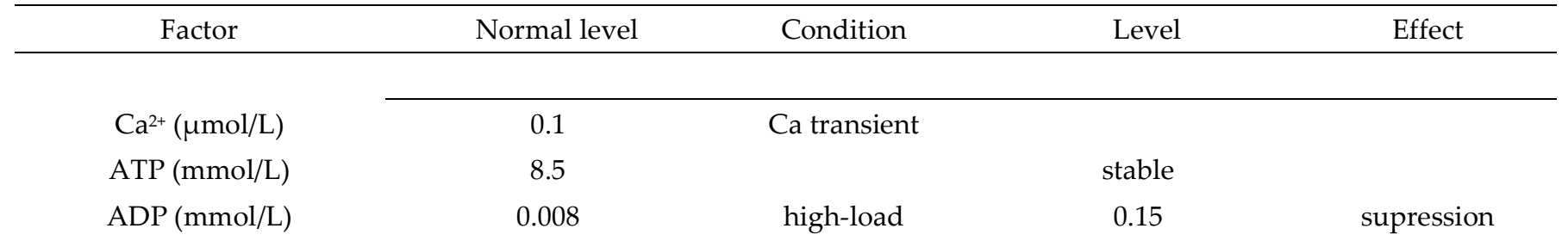




\begin{tabular}{ccccc}
$\mathrm{AMP}(\mu \mathrm{mol} / \mathrm{L})$ & 0.007 & high-load & 2.7 & supression \\
$\mathrm{Mg}^{2+}(\mathrm{mmol} / \mathrm{L})$ & 0.8 & high-load & 1.55 & supression \\
$\mathrm{SR} \mathrm{Ca}(\mathrm{mmol} / \mathrm{L})$ & 0.4 & high-load & 0.08 & supression \\
$\mathrm{pH}$ & 7.0 & exercise & 6.7 & supression \\
$\mathrm{NO}(\mathrm{nmol} / \mathrm{L})$ & $50-200$ & ischemia & 450 & activation \\
$\mathrm{H}_{2} \mathrm{O}_{2}(\mathrm{pmol} / \mathrm{min} / \mathrm{mg})$ & $100-400$ & contusion & $>2$ times & activation \\
$\mathrm{NADH} / \mathrm{NAD}$ ratio & $0.04-0.05$ & ischemia & $>20$ times & activation \\
\hline
\end{tabular}

ADP, adenosine diphosphate; AMP, adenosine monophosphate; ATP, adenosine triphosphate; NAD, nicotinamide adenine dinucleotide; NO, nitric oxide; SR, sarcoplasmic reticulum

\section{Conclusion}

The RyR may not be a simple ion channel, it may act as a sensor and receptor that actively regulates muscular mechanisms. When skeletal muscle is subjected to high-load exercise, the channel activity becomes reduced by alteration of nucleotide composition. After a critical situation occurs because of external stress, injury, or excitement of skeletal or cardiac muscle, changes in redox state and dissociation of inhibitory factors increase channel activity. Since RyRs are submaximally active under normal muscle conditions, they can sense changes in the intracellular environment caused by external influences and perform biphasic modulation of $\mathrm{Ca}^{2+}$ release. The balance of RyR channel activity and biphasic modulation associated with the intracellular environment may be the key to maintaining muscle function, and an imbalance in RyR activity may lead to skeletal muscle disease and/or cardiomyopathy.

Funding: This work was supported in part by the JSPS KAKENHI (grant number 20K11368 to T.K., 19K07105 to N.K., and 19H03404 to T.M.), the Platform Project for Supporting Drug Discovery and Life Science Research (Basis for Supporting Innovative Drug Discovery and Life Science Research (BINDS)) (JP20am0101080 to T.M and N.K.), the Practical Research Project for Rare/Intractable Diseases (19ek0109202 to N.K.) from the Japan Agency for Medical Research and Development (AMED), and an Intramural Research Grant (2-5 to T.M.) for Neurological and Psychiatric Disorders of NCNP, the Vehicle Racing Commemorative Foundation (6114 and 6237 to T.M.).

Acknowledgments: We thank Susan Zunino, PhD, from Edanz (https://jp.edanz.com/ac) for editing a draft of this manuscript.

\section{References}

1. Ogawa, Y.; Kurebayashi, N.; Murayama, T. Ryanodine receptor isoforms in excitation-contraction coupling. Adv. Biophys. 1999, 36, 27-64, doi:10.1016/S0065-227X(99)80004-5.

2. Meissner, G.; Lu, X. Dihydropyridine receptor-ryanodine receptor interactions in skeletal muscle excitation-contraction coupling. Biosci. Rep. 1995, 15, 399-408.

3. Calderón, J.C.; Bolaños, P.; Caputo, C. The excitation-contraction coupling mechanism in skeletal muscle. Biophys. Rev. 2014, $6,133-160$.

4. Holash, R.J.; Macintosh, B.R. A stochastic simulation of skeletal muscle calcium transients in a structurally realistic sarcomere model using mcell. PLoS Comput. Biol. 2019, 15, doi:10.1371/journal.pcbi.1006712.

5. Cannell, M.B.; Allen, D.G. Model of calcium movements during activation in the sarcomere of frog skeletal muscle. Biophys. J. 1984, 45, 913-925, doi:10.1016/S0006-3495(84)84238-1.

6. Baylor, S.M.; Hollingworth, S. Intracellular calcium movements during excitation-contraction coupling in mammalian slow-twitch and fast-twitch muscle fibers. J. Gen. Physiol. 2012, 139, 261-272. 
7. Gomes, A. V.; Potter, J.D.; Szczesna-Cordary, D. The role of troponins in muscle contraction. IUBMB Life 2002, 54, 323-333.

8. El-Saleh, S.C.; Warber, K.D.; Potter, J.D. The role of tropomyosin-troponin in the regulation of skeletal muscle contraction. J. Muscle Res. Cell Motil. 1986, 7, 387-404.

9. Meissner, G. The structural basis of ryanodine receptor ion channel function. J. Gen. Physiol. 2017, 149, 1065-1089.

10. des Georges, A.; Clarke, O.B.; Zalk, R.; Yuan, Q.; Condon, K.J.; Grassucci, R.A.; Hendrickson, W.A.; Marks, A.R.; Frank, J. Structural Basis for Gating and Activation of RyR1. Cell 2016, 167, 145-157.e17, doi:10.1016/j.cell.2016.08.075.

11. Zalk, R.; Clarke, O.B.; Georges, A. Des; Grassucci, R.A.; Reiken, S.; Mancia, F.; Hendrickson, W.A.; Frank, J.; Marks, A.R. Structure of a mammalian ryanodine receptor. Nature 2015, 517, 44-49, doi:10.1038/nature13950.

12. Peng, W.; Shen, H.; Wu, J.; Guo, W.; Pan, X.; Wang, R.; Chen, S.R.W.; Yan, N. Structural basis for the gating mechanism of the type 2 ryanodine receptor RyR2. Science (80-. ). 2016, 354, doi:10.1126/science.aah5324.

13. Betzenhauser, M.J.; Marks, A.R. Ryanodine receptor channelopathies. Pflugers Arch. Eur. J. Physiol. 2010, 460, 467-480.

14. Hymel, L.; Inui, M.; Fleischer, S.; Schindler, H. Purified ryanodine receptor of skeletal muscle sarcoplasmic reticulum forms Ca2+-activated oligomeric Ca2+ channels in planar bilayers. Proc. Natl. Acad. Sci. U. S. A. 1988, doi:10.1073/pnas.85.2.441.

15. Liu, W.; Pasek, D.A.; Meissner, G. Modulation of Ca2+-gated cardiac muscle Ca2+-release channel (ryanodine receptor) by mono- and divalent ions. Am. J. Physiol. - Cell Physiol. 1998, 274, doi:10.1152/ajpcell.1998.274.1.c120.

16. Murayama, T.; Ogawa, Y. Characterization of type 3 Ryanodine receptor (RyR3) of sarcoplasmic reticulum from rabbit skeletal muscles. J. Biol. Chem. 1997, doi:10.1074/jbc.272.38.24030.

17. Murayama, T.; Kurebayashi, N. Two ryanodine receptor isoforms in nonmammalian vertebrate skeletal muscle: Possible roles in excitation-contraction coupling and other processes. Prog. Biophys. Mol. Biol. 2011, 105, 134-144.

18. Pessah, I.N.; Stambuk, R.A.; Casida, J.E. Ca2+-activated ryanodine binding: Mechanisms of sensitivity and intensity modulation by $\mathrm{Mg} 2+$, caffeine, and adenine nucleotides. Mol. Pharmacol. 1987.

19. Laver, D.R.; Lenz, G.K.E.; Lamb, G.D. Regulation of the calcium release channel from rabbit skeletal muscle by the nucleotides ATP, AMP, IMP and adenosine. J. Physiol. 2001, doi:10.1113/jphysiol.2001.012775.

20. Percival, A.L.; Williams, A.J.; Kenyon, J.L.; Grinsell, M.M.; Airey, J.A.; Sutko, J.L. Chicken skeletal muscle ryanodine receptor isoforms: ion channel properties. Biophys. J. 1994, 67, 1834-1850, doi:10.1016/S0006-3495(94)80665-4.

21. Jóna, I.; Szegedi, C.; Sárközi, S.; Szentesi, P.; Csernoch, L.; Kovács, L. Altered inhibition of the rat skeletal ryanodine receptor/calcium release channel by magnesium in the presence of ATP. Pflugers Arch. Eur. J. Physiol. 2001, doi:10.1007/s004240000484.

22. Murayama, T.; Kurebayashi, N.; Ogawa, Y. Role of Mg2+ in Ca2+-induced Ca2+ release through ryanodine receptors of frog skeletal muscle: Modulations by adenine nucleotides and caffeine. Biophys. J. 2000, 78, 1810-1824, doi:10.1016/S0006-3495(00)76731-2.

23. Laver, D.R.; Baynes, T.M.; Dulhunty, A.F. Magnesium inhibition of ryanodine-receptor calcium channels: Evidence for two independent mechanisms. J. Membr. Biol. 1997, 156, 213-229, doi:10.1007/s002329900202.

24. Chan, W.M.; Welch, W.; Sitsapesan, R. Structural factors that determine the ability of adenosine and related compounds to activate the cardiac ryanodine receptor. Br. J. Pharmacol. 2000, doi:10.1038/sj.bjp.0703459.

25. Lanza, I.R.; Wigmore, D.M.; Befroy, D.E.; Kent-Braun, J.A. In vivo ATP production during free-flow and ischaemic muscle contractions in humans. J. Physiol. 2006, 577, 353-367, doi:10.1113/jphysiol.2006.114249.

26. Dias, J.M.; Vogel, P.D. Effects of small molecule modulators on ATP binding to skeletal ryanodine receptor. Protein J. 2009, 28, 240-246, doi:10.1007/s10930-009-9189-9.

27. Ching, L.L.; Williams, A.J.; Sitsapesan, R. Evidence for Ca2+ activation and inactivation sites on the luminal side of the cardiac ryanodine receptor complex. Circ. Res. 2000, doi:10.1161/01.RES.87.3.201. 
28. Chen, W.; Wang, R.; Chen, B.; Zhong, X.; Kong, H.; Bai, Y.; Zhou, Q.; Xie, C.; Zhang, J.; Guo, A.; et al. The ryanodine receptor store-sensing gate controls Ca 2+ waves and Ca2+-triggered arrhythmias. Nat. Med. 2014, 20, 184-192, doi:10.1038/nm.3440.

29. Tencerová, B.; Zahradníková, A.; Gaburjáková, J.; Gaburjáková, M. Luminal Ca 2+ controls activation of the cardiac yanodine receptor by ATP. J. Gen. Physiol. 2012, 140, 93-108, doi:10.1085/jgp.201110708.

30. Kong, H.; Wang, R.; Chen, W.; Zhang, L.; Chen, K.; Shimoni, Y.; Duff, H.J.; Chen, S.R.W. Skeletal and cardiac ryanodine receptors exhibit different responses to Ca2+ overload and luminal Ca2+. Biophys. J. 2007, 92, 2757-2770, doi:10.1529/biophysj.106.100545.

31. Kawasaki, T.; Kasai, M. Regulation of calcium channel in sarcoplasmic reticulum by calsequestrin. Biochem. Biophys. Res. Commun. 1994, 199, 1120-1127, doi:10.1006/bbrc.1994.1347.

32. Donoso, P.; Prieto, H.; Hidalgo, C. Luminal calcium regulates calcium release in triads isolated from frog and rabbit skeletal muscle. Biophys. J. 1995, doi:10.1016/S0006-3495(95)80212-2.

33. Donoso, P.; Beltrán, M.; Hidalgo, C. Luminal $\mathrm{pH}$ regulates calcium release kinetics in sarcoplasmic reticulum vesicles. Biochemistry 1996, 35, 13419-13425, doi:10.1021/bi9616209.

34. Beard, N.A.; Sakowska, M.M.; Dulhunty, A.F.; Laver, D.R. Calsequestrin is an inhibitor of skeletal muscle ryanodine receptor calcium release channels. Biophys. J. 2002, 82, 310-320, doi:10.1016/S0006-3495(02)75396-4.

35. Beard, N.A.; Dulhunty, A.F. C-terminal residues of skeletal muscle calsequestrin are essential for calcium binding and for skeletal ryanodine receptor inhibition. Skelet. Muscle 2015, 5, doi:10.1186/s13395-015-0029-7.

36. Wei, L.; Varsányi, M.; Dulhunty, A.F.; Beard, N.A. The conformation of calsequestrin determines its ability to regulate skeletal ryanodine receptors. Biophys. J. 2006, 91, 1288-1301, doi:10.1529/biophysj.106.082610.

37. Wei, L.; Gallant, E.M.; Dulhunty, A.F.; Beard, N.A. Junctin and triadin each activate skeletal ryanodine receptors but junctin alone mediates functional interactions with calsequestrin. Int. J. Biochem. Cell Biol. 2009, 41, 2214-2224, doi:10.1016/j.biocel.2009.04.017.

38. Goonasekera, S.A.; Beard, N.A.; Groom, L.; Kimura, T.; Lyfenko, A.D.; Rosenfeld, A.; Marty, I.; Dulhunty, A.F.; Dirksen, R.T. Triadin binding to the C-terminal luminal loop of the ryanodine receptor is important for skeletal muscle excitation-contraction coupling. J. Gen. Physiol. 2007, 130, 365-378, doi:10.1085/jgp.200709790.

39. Ziman, A.P.; Ward, C.W.; Rodney, G.G.; Lederer, W.J.; Bloch, R.J. Quantitative measurement of Ca2+ in the sarcoplasmic reticulum lumen of mammalian skeletal muscle. Biophys. J. 2010, 99, 2705-2714, doi:10.1016/j.bpj.2010.08.032.

40. Ma, J.; Zhao, J. Highly cooperative and hysteretic response of the skeletal muscle ryanodine receptor to changes in proton concentrations. Biophys. J. 1994, 67, 626-633, doi:10.1016/S0006-3495(94)80522-3.

41. Kowalchuk, J.M.; Heigenhauser, G.J.F.; Lindinger, M.I.; Sutton, J.R.; Jones, N.L. Factors influencing hydrogen ion concentration in muscle after intense exercise. J. Appl. Physiol. 1988, 65, 2080-2089, doi:10.1152/jappl.1988.65.5.2080.

42. Paolini, C.; Protasi, F.; Franzini-Armstrong, C. The relative position of RyR feet and DHPR tetrads in skeletal muscle. J. Mol. Biol. 2004, 342, 145-153, doi:10.1016/j.jmb.2004.07.035.

43. Huang, C.L.H.; Pedersen, T.H.; Fraser, J.A. Reciprocal dihydropyridine and ryanodine receptor interactions in skeletal muscle activation. J. Muscle Res. Cell Motil. 2011, 32, 171-202.

44. Bers, D.M.; Stiffel, V.M. Ratio of ryanodine to dihydropyridine receptors in cardiac and skeletal muscle and implications for E-C coupling. Am. J. Physiol. - Cell Physiol. 1993, 264, doi:10.1152/ajpcell.1993.264.6.c1587.

45. Flucher, B.E. Skeletal muscle CaV1.1 channelopathies. Pflugers Arch. Eur. J. Physiol. 2020, 472, 739-754.

46. Hopkins, P.M.; Girard, T.; Dalay, S.; Jenkins, B.; Thacker, A.; Patteril, M.; McGrady, E. Malignant hyperthermia 2020: Guideline from the Association of Anaesthetists. Anaesthesia 2021, 76, doi:10.1111/anae.15317.

47. Jayaraman, T.; Brillantes, A.M.; Timerman, A.P.; Fleischer, S.; Erdjument-Bromage, H.; Tempst, P.; Marks, A.R. FK506 binding protein associated with the calcium release channel (ryanodine receptor). J. Biol. Chem. 1992. 
48. Timerman, A.P.; Jayaraman, T.; Wiederrecht, G.; Onoue, H.; Marks, A.R.; Fleischer, S. The ryanodine receptor from canine heart sarcoplasmic reticulum is associated with a novel FK-506 binding protein. Biochem. Biophys. Res. Commun. 1994, doi:10.1006/bbrc.1994.1101.

49. Timerman, A.P.; Onoue, H.; Xin, H.B.; Barg, S.; Copello, J.; Wiederrecht, G.; Fleischer, S. Selective binding of FKBP12.6 by the cardiac ryanodine receptor. J. Biol. Chem. 1996, doi:10.1074/jbc.271.34.20385.

50. Lam, E.; Martin, M.M.; Timerman, A.P.; Sabers, C.; Fleischer, S.; Lukas, T.; Abraham, R.T.; O'Keefe, S.J.; O’Neill, E.A.; Wiederrecht, G.J. A novel FK506 binding protein can mediate the immunosuppressive effects of FK506 and is associated with the cardiac ryanodine receptor. J. Biol. Chem. 1995, doi:10.1074/jbc.270.44.26511.

51. Gaburjakova, M.; Gaburjakova, J.; Reiken, S.; Huang, F.; Marx, S.O.; Rosemblit, N.; Marks, A.R. FKBP12 Binding Modulates Ryanodine Receptor Channel Gating. J. Biol. Chem. 2001, doi:10.1074/jbc.M100856200.

52. O'Reilly, F.M.; Robert, M.; Jona, I.; Szegedi, C.; Albrieux, M.; Geib, S.; De Waard, M.; Villaz, M.; Ronjat, M. FKBP12 modulation of the binding of the skeletal ryanodine receptor onto the II-III loop of the dihydropyridine receptor. Biophys. J. 2002, 82, 145-155, doi:10.1016/S0006-3495(02)75381-2.

53. Marx, S.O.; Reiken, S.; Hisamatsu, Y.; Jayaraman, T.; Burkhoff, D.; Rosemblit, N.; Marks, A.R. PKA phosphorylation dissociates FKBP12.6 from the calcium release channel (ryanodine receptor): Defective regulation in failing hearts. Cell 2000, 101, 365-376, doi:10.1016/S0092-8674(00)80847-8.

54. MacMillan, D.; Currie, S.; McCarron, J.G. FK506-binding protein (FKBP12) regulates ryanodine receptor-evoked Ca2+ release in colonic but not aortic smooth muscle. Cell Calcium 2008, doi:10.1016/j.ceca.2007.09.002.

55. Xu, L.; Gomez, A.C.; Pasek, D.A.; Meissner, G.; Yamaguchi, N. Two EF-hand motifs in ryanodine receptor calcium release channels contribute to isoform-specific regulation by calmodulin. Cell Calcium 2017, doi:10.1016/j.ceca.2017.05.013.

56. Ikemoto, T.; Iino, M.; Endo, M. Enhancing effect of calmodulin on $\mathrm{Ca}(2+)$-induced $\mathrm{Ca} 2+$ release in the sarcoplasmic reticulum of rabbit skeletal muscle fibres. J. Physiol. 1995, doi:10.1113/jphysiol.1995.sp020901.

57. Boschek, C.B.; Jones, T.E.; Squier, T.C.; Bigelow, D.J. Calcium occupancy of N-terminal sites within calmodulin induces inhibition of the ryanodine receptor calcium release channel. Biochemistry 2007, doi:10.1021/bi700655h.

58. Tripathy, A.; Xu, L.; Mann, G.; Meissner, G. Calmodulin activation and inhibition of skeletal muscle Ca2+ release channel (ryanodine receptor). Biophys. J. 1995, doi:10.1016/S0006-3495(95)79880-0.

59. Xu, L.; Meissner, G. Mechanism of Calmodulin Inhibition of Cardiac Sarcoplasmic Reticulum Ca2+ Release Channel (Ryanodine Receptor). Biophys. J. 2004, 86, 797-804, doi:10.1016/S0006-3495(04)74155-7.

60. Gong, D.; Chi, X.; Wei, J.; Zhou, G.; Huang, G.; Zhang, L.; Wang, R.; Lei, J.; Chen, S.R.W.; Yan, N. Modulation of cardiac ryanodine receptor 2 by calmodulin. Nature 2019, doi:10.1038/s41586-019-1377-y.

61. Ma, R.; Haji-Ghassemi, O.; Ma, D.; Jiang, H.; Lin, L.; Yao, L.; Samurkas, A.; Li, Y.; Wang, Y.; Cao, P.; et al. Structural basis for diamide modulation of ryanodine receptor. Nat. Chem. Biol. 2020, 16, 1246-1254, doi:10.1038/s41589-020-0627-5.

62. Prosser, B.L.; Wright, N.T.; Hernãndez-Ochoa, E.O.; Varney, K.M.; Liu, Y.; Olojo, R.O.; Zimmer, D.B.; Weber, D.J.; Schneider, M.F. S100A1 binds to the calmodulin-binding site of ryanodine receptor and modulates skeletal muscle excitation-contraction coupling. J. Biol. Chem. 2008, 283, 5046-5057, doi:10.1074/jbc.M709231200.

63. Witcher, D.R.; Strifler, B.A.; Jones, L.R. Cardiac-specific phosphorylation site for multifunctional Ca2+/calmodulin-dependent protein kinase is conserved in the brain ryanodine receptor. J. Biol. Chem. 1992.

64. Dulhunty, A.F.; Laver, D.; Curtis, S.M.; Pace, S.; Haarmann, C.; Gallant, E.M. Characteristics of irreversible ATP activation suggest that native skeletal ryanodine receptors can be phosphorylated via an endogenous CaMKII. Biophys. J. 2001, 81, 3240-3252, doi:10.1016/S0006-3495(01)75959-0.

65. Becerra, R.; Román, B.; Di Carlo, M.N.; Mariangelo, J.I.; Salas, M.; Sanchez, G.; Donoso, P.; Schinella, G.R.; Vittone, L.; Wehrens, X.H.; et al. Reversible redox modifications of ryanodine receptor ameliorate ventricular arrhythmias in the ischemic-reperfused heart. Am. J. Physiol. - Hear. Circ. Physiol. 2016, doi:10.1152/ajpheart.00142.2016. 
66. Eu, J.P.; Xu, L.; Stamler, J.S.; Meissner, G. Regulation of ryanodine receptors by reactive nitrogen species. Biochem. Pharmacol. 1999, doi:10.1016/S0006-2952(98)00360-8.

67. Suko, J.; Drobny, H.; Hellmann, G. Activation and inhibition of purified skeletal muscle calcium release channel by NO donors in single channel current recordings. Biochim. Biophys. Acta - Mol. Cell Res. 1999, doi:10.1016/S0167-4889(99)00098-1.

68. Aracena, P.; Sánchez, G.; Donoso, P.; Hamilton, S.L.; Hidalgo, C. S-Glutathionylation Decreases Mg2+ Inhibition and S-Nitrosylation Enhances Ca2+ Activation of RyR1 Channels. J. Biol. Chem. 2003, doi:10.1074/jbc.M306969200.

69. Sun, J.; Xu, L.; Eu, J.P.; Stamler, J.S.; Meissner, G. Nitric oxide, NOC-12, and S-nitrosoglutathione modulate the skeletal muscle calcium release channel/ryanodine receptor by different mechanisms: An allosteric function for $\mathrm{O} 2$ in S-nitrosylation of the channel. J. Biol. Chem. 2003, doi:10.1074/jbc.M211940200.

70. Aracena, P.; Tang, W.; Hamilton, S.L.; Hidalgo, C. Effects of S-glutathionylation and S-nitrosylation on calmodulin binding to triads and FKBP12 binding to type 1 calcium release channels. Antioxidants Redox Signal. 2005, doi:10.1089/ars.2005.7.870.

71. Kumasaka, S.; Shoji, H.; Okabe, E. Novel Mechanisms Involved in Superoxide Anion Radical-Triggered Ca2+ Release from Cardiac Sarcoplasmic Reticulum Linked to Cyclic ADP-Ribose Stimulation. Antioxidants Redox Signal. 1999, doi:10.1089/ars.1999.1.1-55.

72. Oda, T.; Yang, Y.; Uchinoumi, H.; Thomas, D.D.; Chen-Izu, Y.; Kato, T.; Yamamoto, T.; Yano, M.; Cornea, R.L.; Bers, D.M. Oxidation of ryanodine receptor (RyR) and calmodulin enhance Ca release and pathologically alter, RyR structure and calmodulin affinity. J. Mol. Cell. Cardiol. 2015, 85, 240-248, doi:10.1016/j.yjmcc.2015.06.009.

73. Bombicino, S.S.; Iglesias, D.E.; Rukavina-Mikusic, I.A.; Buchholz, B.; Gelpi, R.J.; Boveris, A.; Valdez, L.B. Hydrogen peroxide, nitric oxide and ATP are molecules involved in cardiac mitochondrial biogenesis in Diabetes. Free Radic. Biol. Med. 2017, 112, 267-276, doi:10.1016/j.freeradbiomed.2017.07.027.

74. Goncalves, R.L.S.; Quinlan, C.L.; Perevoshchikova, I. V.; Hey-Mogensen, M.; Brand, M.D. Sites of superoxide and hydrogen peroxide production by muscle mitochondria assessed ex vivo under conditions mimicking rest and exercise. J. Biol. Chem. 2015, 290, 209-227.

75. Munro, D.; Banh, S.; Sotiri, E.; Tamanna, N.; Treberg, J.R. The thioredoxin and glutathione-dependent $\mathrm{H} 2 \mathrm{O} 2$ consumption pathways in muscle mitochondria: Involvement in $\mathrm{H} 2 \mathrm{O} 2$ metabolism and consequence to $\mathrm{H} 2 \mathrm{O} 2$ efflux assays. Free Radic. Biol. Med. 2016, 96, 334-346, doi:10.1016/j.freeradbiomed.2016.04.014.

76. Miller, V.J.; LaFountain, R.A.; Barnhart, E.; Sapper, T.S.; Short, J.; David Arnold, W.; Hyde, P.N.; Crabtree, C.D.; Kackley, M.L.; Kraemer, W.J.; et al. A ketogenic diet combined with exercise alters mitochondrial function in human skeletal muscle while improving metabolic health. Am. J. Physiol. - Endocrinol. Metab. 2020, 319, E995-E1007, doi:10.1152/AJPENDO.00305.2020.

77. Favero, T.G.; Zable, A.C.; Bowman, M.B.; Thompson, A.; Abramson, J.J. Metabolic end products inhibit sarcoplasmic reticulum Ca2+ release and [3H]ryanodine binding. J. Appl. Physiol. 1995, doi:10.1152/jappl.1995.78.5.1665.

78. Aghdasi, B.; Reid, M.B.; Hamilton, S.L. Nitric oxide protects the skeletal muscle Ca2+ release channel from oxidation induced activation. J. Biol. Chem. 1997, doi:10.1074/jbc.272.41.25462.

79. Zissimopoulos, S.; Docrat, N.; Lai, F.A. Redox sensitivity of the ryanodine receptor interaction with FK506-binding protein. J. Biol. Chem. 2007, doi:10.1074/jbc.M607590200.

80. Liao, B.; Zheng, Y.M.; Yadav, V.R.; Korde, A.S.; Wang, Y.X. Hypoxia induces intracellular Ca2+ release by causing reactive oxygen species-mediated dissociation of FK506-binding protein 12.6 from ryanodine receptor 2 in pulmonary artery myocytes. Antioxidants Redox Signal. 2011, doi:10.1089/ars.2009.3047.

81. Hanna, A.D.; Lam, A.; Thekkedam, C.; Gallant, E.M.; Beard, N.A.; Dulhunty, A.F. Cardiac ryanodine receptor activation by a high Ca 2+ store load is reversed in a reducing cytoplasmic redox environment. J. Cell Sci. 2014, 127, 4531-4541, doi:10.1242/jcs.156760. 
82. Zima, A. V.; Copello, J.A.; Blatter, L.A. Differential modulation of cardiac and skeletal muscle ryanodine receptors by NADH. FEBS Lett. 2003, doi:10.1016/S0014-5793(03)00664-1.

83. Sahlin, K. NADH in human skeletal muscle during short-term intense exercise. Pflügers Arch. Eur. J. Physiol. 1985, 403, 193196, doi:10.1007/BF00584099.

84. Henriksson, J.; Katz, A.; Sahlin, K. Redox state changes in human skeletal muscle after isometric contraction. J. Physiol. 1986, 380, 441-451, doi:10.1113/jphysiol.1986.sp016296.

85. Sahlin, K.; Katz, A.; Henriksson, J. Redox state and lactate accumulation in human skeletal muscle during dynamic exercise. Biochem. J. 1987, 245, 551-556, doi:10.1042/bj2450551.

86. Green, H.J.; Jones, S.; Ball-Burnett, M.; Farrance, B.; Ranney, D. Adaptations in muscle metabolism to prolonged voluntary exercise and training. J. Appl. Physiol. 1995, 78, 138-145, doi:10.1152/jappl.1995.78.1.138.

87. Zima, A. V.; Copello, J.A.; Blatter, L.A. Effects of cytosolic NADH/NAD+ levels on sarcoplasmic reticulum Ca2+ release in permeabilized rat ventricular myocytes. J. Physiol. 2004, 555, 727-741, doi:10.1113/jphysiol.2003.055848.

88. Kobayashi, K.; Neely, J.R. Mechanism of pyruvate dehydrogenase activation by increased cardiac work. J. Mol. Cell. Cardiol. 1983, 15, 369-382, doi:10.1016/0022-2828(83)90321-8.

89. Park, J.W.; Chun, Y.S.; Kim, M.S.; Park, Y.C.; Kwak, S.J.; Park, S.C. Metabolic modulation of cellular redox potential can improve cardiac recovery from ischemia-reperfusion injury. Int. J. Cardiol. 1998, 65, 139-147, doi:10.1016/S0167-5273(98)00117-X.

90. Zhou, L.; Cabrera, M.E.; Okere, I.C.; Sharma, N.; Stanley, W.C. Regulation of myocardial substrate metabolism during increased energy expenditure: Insights from computational studies. Am. J. Physiol. - Hear. Circ. Physiol. 2006, 291, doi:10.1152/ajpheart.01382.2005.

91. Fulceri, R.; Knudsen, J.; Giunti, R.; Volpe, P.; Nori, A.; Benedetti, A. Fatty acyl-CoA-acyl-CoA-binding protein complexes activate the Ca2+ release channel of skeletal muscle sarcoplasmic reticulum. Biochem. J. 1997, doi:10.1042/bj3250423.

92. el-Hayek, R.; Valdivia, C.; Valdivia, H.H.; Hogan, K.; Coronado, R. Activation of the Ca2+ release channel of skeletal muscle sarcoplasmic reticulum by palmitoyl carnitine. Biophys. J. 1993, doi:10.1016/S0006-3495(93)81101-9.

93. Connelly, T.; Ahern, C.; Sukhareva, M.; Coronado, R. Removal of Mg2+ inhibition of cardiac ryanodine receptor by palmitoyl coenzyme A. FEBS Lett. 1994, doi:10.1016/0014-5793(94)00969-4.

94. Fulceri, R.; Giunti, R.; Knudsen, J.; Leuzzi, R.; Kardon, T.; Benedetti, A. Rapamycin inhibits activation of ryanodine receptors from skeletal muscle by the fatty acyl CoA-acyl CoA binding protein complex. Biochem. Biophys. Res. Commun. 1999, doi:10.1006/bbrc.1999.1532.

95. Sharma, C.; Smith, T.; Li, S.; Schroepfer, G.J.; Needleman, D.H. Inhibition of Ca2+ release channel (ryanodine receptor) activity by sphingolipid bases: Mechanism of action. Chem. Phys. Lipids 2000, doi:10.1016/S0009-3084(99)00106-1.

96. Sakurai, T.; Kashimura, O.; Kano, Y.; Ohno, H.; Ji, L.L.; Izawa, T.; Best, T.M. Role of nitric oxide in muscle regeneration following eccentric muscle contractions in rat skeletal muscle. J. Physiol. Sci. 2013, doi:10.1007/s12576-013-0262-y.

97. Loureiro, A.C.C.; Rêgo-Monteiro, I.C. Do; Louzada, R.A.; Ortenzi, V.H.; Aguiar, A.P. De; Abreu, E.S. De; Cavalcanti-De-Albuquerque, J.P.A.; Hecht, F.; Oliveira, A.C. De; Ceccatto, V.M.; et al. Differential Expression of NADPH Oxidases Depends on Skeletal Muscle Fiber Type in Rats. Oxid. Med. Cell. Longev. 2016, doi:10.1155/2016/6738701.

98. Espinosa, A.; Leiva, A.; Peña, M.; Müller, M.; Debandi, A.; Hidalgo, C.; Angélica Carrasco, M.; Jaimovich, E. Myotube depolarization generates reactive oxygen species through NAD $(\mathrm{P}) \mathrm{H}$ oxidase; ROS-elicited Ca2+ stimulates ERK, CREB, early genes. J. Cell. Physiol. 2006, doi:10.1002/jcp.20745.

99. Baumann, C.W.; Rogers, R.G.; Gahlot, N.; Ingalls, C.P. Eccentric contractions disrupt FKBP12 content in mouse skeletal muscle. Physiol. Rep. 2014, doi:10.14814/phy2.12081.

100. Allen, D.; Lännergren, J.; Westerblad, H. Intracellular ATP measured with luciferin/luciferase in isolated single mouse skeletal muscle fibres. Pflugers Arch. Eur. J. Physiol. 2002, 443, 836-842, doi:10.1007/s00424-001-0756-y. 
101. Dutka, T.L.; Lamb, G.D. Effect of low cytoplasmic [ATP] on excitation-contraction coupling in fast-twitch muscle fibres of the rat. J. Physiol. 2004, doi:10.1113/jphysiol.2004.069112.

102. Westerblad, H.; Allen, D.G. Myoplasmic free Mg2+ concentration during repetitive stimulation of single fibres from mouse skeletal muscle. J. Physiol. 1992, 453, 413-434, doi:10.1113/jphysiol.1992.sp019236.

103. Korzeniewski, B.; Rossiter, H.B. Exceeding a “critical” muscle Pi: implications for V · O 2 and metabolite slow components, muscle fatigue and the power-duration relationship. Eur. J. Appl. Physiol. 2020, 120, 1609-1619, doi:10.1007/s00421-020-04388-4.

104. Bertocci, L.A.; Fleckenstein, J.L.; Antonio, J. Human muscle fatigue after glycogen depletion: A 31P magnetic resonance study. J. Appl. Physiol. 1992, 73, 75-81, doi:10.1152/jappl.1992.73.1.75.

105. Hartmann, D.D.; Gonçalves, D.F.; Da Rosa, P.C.; Martins, R.P.; Courtes, A.A.; Franco, J.L.; Félix, F.A.; Puntel, G.O. A single muscle contusion promotes an immediate alteration in mitochondrial bioenergetics response in skeletal muscle fibres with different metabolism. Free Radic. Res. 2020, 54, 137-149, doi:10.1080/10715762.2020.1723795.

106. Kerkweg, U.; Schmitz, D.; De Groot, H. Screening for the formation of reactive oxygen species and of NO in muscle tissue and remote organs upon mechanical trauma to the mouse hind limb. Eur. Surg. Res. 2006, 38, 83-89, doi:10.1159/000092609.

107. Kerkweg, U.; Petrat, F.; Korth, H.G.; De Groot, H. Disruption of skeletal myocytes initiates superoxide release: Contribution of NAD(P)H oxidase. Shock 2007, 27, 552-558, doi:10.1097/01.shk.0000245027.39483.e4.

108. Volodina, O.; Ganesan, S.; Pearce, S.C.; Gabler, N.K.; Baumgard, L.H.; Rhoads, R.P.; Selsby, J.T. Short-term heat stress alters redox balance in porcine skeletal muscle. Physiol. Rep. 2017, 5, doi:10.14814/phy2.13267.

109. Kikusato, M.; Toyomizu, M. Crucial Role of Membrane Potential in Heat Stress-Induced Overproduction of Reactive Oxygen Species in Avian Skeletal Muscle Mitochondria. PLoS One 2013, 8, doi:10.1371/journal.pone.0064412.

110. Kim, K.; Reid, B.A.; Casey, C.A.; Bender, B.E.; Ro, B.; Song, Q.; Trewin, A.J.; Petersen, A.C.; Kuang, S.; Gavin, T.P.; et al. Effects of repeated local heat therapy on skeletal muscle structure and function in humans. J. Appl. Physiol. 2020, 128, 483492, doi:10.1152/japplphysiol.00701.2019.

111. Durham, W.J.; Aracena-Parks, P.; Long, C.; Rossi, A.E.; Goonasekera, S.A.; Boncompagni, S.; Galvan, D.L.; Gilman, C.P.; Baker, M.R.; Shirokova, N.; et al. RyR1 S-Nitrosylation Underlies Environmental Heat Stroke and Sudden Death in Y522S RyR1 Knockin Mice. Cell 2008, doi:10.1016/j.cell.2008.02.042.

112. Min, K.; Smuder, A.J.; Kwon, O.S.; Kavazis, A.N.; Szeto, H.H.; Powers, S.K. Mitochondrial-targeted antioxidants protect skeletal muscle against immobilization-induced muscle atrophy. J. Appl. Physiol. 2011, 111, 1459-1466, doi:10.1152/japplphysiol.00591.2011.

113. Uda, M.; Yoshihara, T.; Ichinoseki-Sekine, N.; Baba, T.; Yoshioka, T. Potential roles of neuronal nitric oxide synthase and the PTEN-induced kinase 1 (PINK1)/Parkin pathway for mitochondrial protein degradation in disuse-induced soleus muscle atrophy in adult rats. PLoS One 2020, 15, doi:10.1371/journal.pone.0243660.

114. Hord, J.M.; Garcia, M.M.; Farris, K.R.; Guzzoni, V.; Lee, Y.; Lawler, M.S.; Lawler, J.M. Nox2 signaling and muscle fiber remodeling are attenuated by losartan administration during skeletal muscle unloading. Physiol. Rep. 2021, 9, doi:10.14814/phy2.14606.

115. Viganò, A.; Ripamonti, M.; De Palma, S.; Capitanio, D.; Vasso, M.; Wait, R.; Lundby, C.; Cerretelli, P.; Gelfi, C. Proteins modulation in human skeletal muscle in the early phase of adaptation to hypobaric hypoxia. Proteomics 2008, 8, 4668-4679, doi:10.1002/pmic.200800232.

116. Agrawal, A.; Rathor, R.; Kumar, R.; Suryakumar, G.; Singh, S.N.; Kumar, B. Redox modification of ryanodine receptor contributes to impaired Ca2+ homeostasis and exacerbates muscle atrophy under high altitude. Free Radic. Biol. Med. 2020, 160, 643-656, doi:10.1016/j.freeradbiomed.2020.09.001. 
117. Qaisar, R.; Bhaskaran, S.; Premkumar, P.; Ranjit, R.; Natarajan, K.S.; Ahn, B.; Riddle, K.; Claflin, D.R.; Richardson, A.; Brooks, S. V.; et al. Oxidative stress-induced dysregulation of excitation-contraction coupling contributes to muscle weakness. J. Cachexia. Sarcopenia Muscle 2018, 9, 1003-1017, doi:10.1002/jcsm.12339.

118. Renganathan, M.; Messi, M.L.; Delbono, O. Dihydropyridine receptor-ryanodine receptor uncoupling in aged skeletal muscle. J. Membr. Biol. 1997, 157, 247-253, doi:10.1007/s002329900233.

119. Potenza, D.M.; Janicek, R.; Fernandez-Tenorio, M.; Camors, E.; Ramos-Mondragón, R.; Valdivia, H.H.; Niggli, E. Phosphorylation of the ryanodine receptor 2 at serine 2030 is required for a complete $\beta$-adrenergic response. J. Gen. Physiol. 2019, doi:10.1085/jgp.201812155.

120. Ullrich, N.D.; Valdivia, H.H.; Niggli, E. PKA phosphorylation of cardiac ryanodine receptor modulates SR luminal Ca 2+ sensitivity. J. Mol. Cell. Cardiol. 2012, doi:10.1016/j.yjmcc.2012.03.015.

121. Veneroso, C.; Tuñón, M.J.; González-Gallego, J.; Collado, P.S. Melatonin reduces cardiac inflammatory injury induced by acute exercise. J. Pineal Res. 2009, doi:10.1111/j.1600-079X.2009.00699.x.

122. Bellafiore, M.; Battaglia, G.; Bianco, A.; Palma, A. Expression pattern of angiogenic factors in healthy heart in response to physical exercise intensity. Front. Physiol. 2019, doi:10.3389/fphys.2019.00238.

123. Winlaw, D.S.; Keogh, A.M.; Schyvens, C.G.; Spratt, P.M.; Macdonald, P.S.; Smythe, G.A. Increased nitric oxide production in heart failure. Lancet 1994, 344, 373-374, doi:10.1016/S0140-6736(94)91403-6.

124. Drexler, H.; Kästner, S.; Strobel, A.; Studer, R.; Brodde, O.E.; Hasenfuß, G. Expression, activity and functional significance of inducible nitric oxide synthase in the failing human heart. J. Am. Coll. Cardiol. 1998, 32, 955-963, doi:10.1016/S0735-1097(98)00336-2.

125. Bkaily, G.; Najibeddine, W.; Jacques, D. Increase of nadph oxidase 3 in heart failure of hereditary cardiomyopathy. Can. J. Physiol. Pharmacol. 2019, 97, 902-908, doi:10.1139/cjpp-2019-0055.

126. Dworakowski, R.; Walker, S.; Momin, A.; Desai, J.; El-Gamel, A.; Wendler, O.; Kearney, M.T.; Shah, A.M. Reduced Nicotinamide Adenine Dinucleotide Phosphate Oxidase-Derived Superoxide and Vascular Endothelial Dysfunction in Human Heart Failure. J. Am. Coll. Cardiol. 2008, 51, 1349-1356, doi:10.1016/j.jacc.2007.12.033.

127. Brandes, R.P.; Weissmann, N.; Schröder, K. Nox family NADPH oxidases: Molecular mechanisms of activation. Free Radic. Biol. Med. 2014, 76, 208-226.

128. Schröder, K. NADPH oxidase-derived reactive oxygen species: Dosis facit venenum. Exp. Physiol. $2019,104,447-452$.

129. Ono, K.; Yano, M.; Ohkusa, T.; Kohno, M.; Hisaoka, T.; Tanigawa, T.; Kobayashi, S.; Kohno, M.; Matsuzaki, M. Altered interaction of FKBP12.6 with ryanodine receptor as a cause of abnormal Ca2+ release in heart failure. Cardiovasc. Res. 2000, 48, 323-331, doi:10.1016/S0008-6363(00)00191-7.

130. Yano, M.; Ono, K.; Ohkusa, T.; Suetsugu, M.; Kohno, M.; Hisaoka, T.; Kobayashi, S.; Hisamatsu, Y.; Yamamoto, T.; Kohno, M.; et al. Altered stoichiometry of FKBP12.6 versus ryanodine receptor as a cause of abnormal Ca2+ leak through ryanodine receptor in heart failure. Circulation 2000, 102, 2131-2136, doi:10.1161/01.CIR.102.17.2131.

131. Anderson, M.E.; Brown, J.H.; Bers, D.M. CaMKII in myocardial hypertrophy and heart failure. J. Mol. Cell. Cardiol. 2011, 51, 468-473.

132. Kreusser, M.M.; Backs, J. Integrated mechanisms of CaMKII-dependent ventricular remodeling. Front. Pharmacol. 2014, 5 MAR.

133. Vincent, K.P.; McCulloch, A.D.; Edwards, A.G. Toward a hierarchy of mechanisms in CaMKII-mediated arrhythmia. Front. Pharmacol. 2014, 5 MAY.

134. Kato, T.; Yamamoto, T.; Nakamura, Y.; Nanno, T.; Fukui, G.; Sufu, Y.; Hamada, Y.; Maeda, T.; Nishimura, S.; Ishiguchi, H.; et al. Correction of impaired calmodulin binding to RyR2 as a novel therapy for lethal arrhythmia in the pressure-overloaded heart failure. Hear. Rhythm 2017, 14, 120-127, doi:10.1016/j.hrthm.2016.10.019. 
135. Nakamura, Y.; Yamamoto, T.; Kobayashi, S.; Tamitani, M.; Hamada, Y.; Fukui, G.; Xu, X.; Nishimura, S.; Kato, T.; Uchinoumi, H.; et al. Ryanodine receptor-bound calmodulin is essential to protect against catecholaminergic polymorphic ventricular tachycardia. JCI Insight 2019, doi:10.1172/jci.insight.126112.

136. Fauconnier, J.; Meli, A.C.; Thireau, J.; Roberge, S.; Shan, J.; Sassi, Y.; Reiken, S.R.; Rauzier, J.M.; Marchand, A.; Chauvier, D.; et al. Ryanodine receptor leak mediated by caspase-8 activation leads to left ventricular injury after myocardial ischemia-reperfusion. Proc. Natl. Acad. Sci. U. S. A. 2011, doi:10.1073/pnas.1100286108.

137. Di Carlo, M.N.; Said, M.; Ling, H.; Valverde, C.A.; De Giusti, V.C.; Sommese, L.; Palomeque, J.; Aiello, E.A.; Skapura, D.G.; Rinaldi, G.; et al. CaMKII-dependent phosphorylation of cardiac ryanodine receptors regulates cell death in cardiac ischemia/reperfusion injury. J. Mol. Cell. Cardiol. 2014, doi:10.1016/j.yjmcc.2014.06.004.

138. Cadenas, S. ROS and redox signaling in myocardial ischemia-reperfusion injury and cardioprotection. Free Radic. Biol. Med. $2018,117,76-89$.

139. Granger, D.N.; Kvietys, P.R. Reperfusion injury and reactive oxygen species: The evolution of a concept. Redox Biol. 2015, 6, 524-551, doi:10.1016/j.redox.2015.08.020.

140. Deng, J.; Wang, G.; Huang, Q.; Yan, Y.; Li, K.; Tan, W.; Jin, C.; Wang, Y.; Liu, J. Oxidative stress-induced leaky sarcoplasmic reticulum underlying acute heart failure in severe burn trauma. Free Radic. Biol. Med. 2008,

doi:10.1016/j.freeradbiomed.2007.09.023.

141. Rullman, E.; Andersson, D.C.; Melin, M.; Reiken, S.; Mancini, D.; Marks, A.R.; Lund, L.H.; Gustafsson, T. Modifications of the Skeletal Muscle Ryanodine Receptor Type 1 and Exercise Intolerance in Heart Failure. J. Hear. Lung Transplant. 2013, doi:10.1016/j.healun.2013.01.641.

142. Reiken, S.; Lacampagne, A.; Zhou, H.; Kherani, A.; Lehnart, S.E.; Ward, C.; Huang, F.; Gaburjakova, M.; Gaburjakova, J.; Rosemblit, N.; et al. PKA phosphorylation activates the calcium release channel (ryanodine receptor)-in skeletal muscle: Defective regulation in heart failure. J. Cell Biol. 2003, doi:10.1083/jcb.200211012.

143. Pinho, R.A.; Sepa-Kishi, D.M.; Bikopoulos, G.; Wu, M. V.; Uthayakumar, A.; Mohasses, A.; Hughes, M.C.; Perry, C.G.R.; Ceddia, R.B. High-fat diet induces skeletal muscle oxidative stress in a fiber type-dependent manner in rats. Free Radic. Biol. Med. 2017, 110, 381-389, doi:10.1016/j.freeradbiomed.2017.07.005.

144. Jain, S.S.; Paglialunga, S.; Vigna, C.; Ludzki, A.; Herbst, E.A.; Lally, J.S.; Schrauwen, P.; Hoeks, J.; Tupling, A.R.; Bonen, A.; et al. High-fat diet-induced mitochondrial biogenesis is regulated by mitochondrial-derived reactive oxygen species activation of CaMKII. Diabetes 2014, 63, 1907-1913, doi:10.2337/db13-0816.

145. Qi, J.; Luo, X.; Ma, Z.; Zhang, B.; Li, S.; Duan, X.; Yang, B.; Zhang, J. Swimming Exercise Protects against Insulin Resistance via Regulating Oxidative Stress through Nox4 and AKT Signaling in High-Fat Diet-Fed Mice. J. Diabetes Res. 2020, doi:10.1155/2020/2521590.

146. Roussel, J.; Thireau, J.; Brenner, C.; Saint, N.; Scheuermann, V.; Lacampagne, A.; Le Guennec, J.Y.; Fauconnier, J. Palmitoyl-carnitine increases RyR2 oxidation and sarcoplasmic reticulum 1. Roussel J, Thireau J, Brenner C, Saint N, Scheuermann V, Lacampagne A, et al. Palmitoyl-carnitine increases RyR2 oxidation and sarcoplasmic reticulum Ca2+ leak in cardiomyocytes: R. Biochim. Biophys. Acta - Mol. Basis Dis. 2015, doi:10.1016/j.bbadis.2015.01.011.

147. Honen, B.N.; Saint, D.A.; Laver, D.R. Suppression of Calcium Sparks in Rat Ventricular Myocytes and Direct Inhibition of Sheep Cardiac RyR Channels by EPA, DHA and Oleic Acid. J. Membr. Biol. 2003, doi:10.1007/s00232-003-0628-9.

148. Swan, J.S.; Dibb, K.; Negretti, N.; O’Neill, S.C.; Sitsapesan, R. Effects of eicosapentaenoic acid on cardiac SR Ca2+-release and ryanodine receptor function. Cardiovasc. Res. 2003, doi:10.1016/S0008-6363(03)00545-5.

149. Kim, S.H.; Park, Y.; Lim, J.W.; Kim, H. Effect of docosahexaenoic acid on Ca2+ signaling pathways in cerulein-treated pancreatic acinar cells, determined by RNA-sequencing analysis. Nutrients 2019, 11, doi:10.3390/nu11071445.

150. Popescu, I.; Yin, G.; Velmurugan, S.; Erickson, J.R.; Despa, F.; Despa, S. Lower sarcoplasmic reticulum Ca2+ threshold for triggering afterdepolarizations in diabetic rat hearts. Hear. Rhythm 2019, 16, 765-772, doi:10.1016/j.hrthm.2018.11.001. 
151. Shao, C.H.; Tian, C.; Ouyang, S.; Moore, C.J.; Alomar, F.; Nemet, I.; D’Souza, A.; Nagai, R.; Kutty, S.; Rozanski, G.J.; et al. Carbonylation induces heterogeneity in cardiac ryanodine receptor function in diabetes mellitus. Mol. Pharmacol. 2012, 82, 383-399, doi:10.1124/mol.112.078352.

152. Warren, J.L.; Bulur, S.; Ovalle, F.; Windham, S.T.; Gower, B.A.; Fisher, G. Effects of acute hyperinsulinemia on skeletal muscle mitochondrial function, reactive oxygen species production, and metabolism in premenopausal women. Metabolism. 2017, 77, 1-12, doi:10.1016/j.metabol.2017.08.004.

153. Sommese, L.; Valverde, C.A.; Blanco, P.; Castro, M.C.; Rueda, O.V.; Kaetzel, M.; Dedman, J.; Anderson, M.E.; Mattiazzi, A.; Palomeque, J. Ryanodine receptor phosphorylation by CaMKII promotes spontaneous Ca2 + release events in a rodent model of early stage diabetes: The arrhythmogenic substrate. Int. J. Cardiol. 2016, 202, 394-406, doi:10.1016/j.ijcard.2015.09.022.

154. Yaras, N.; Ugur, M.; Ozdemir, S.; Gurdal, H.; Purali, N.; Lacampagne, A.; Vassort, G.; Turan, B. Effects of diabetes on ryanodine receptor Ca release channel (RyR2) and Ca2+ homeostasis in rat heart. Diabetes 2005, 54, 3082-3088, doi:10.2337/diabetes.54.11.3082.

155. Shao, C.H.; Rozanski, G.J.; Patel, K.P.; Bidasee, K.R. Dyssynchronous (non-uniform) Ca2+ release in myocytes from streptozotocin-induced diabetic rats. J. Mol. Cell. Cardiol. 2007, 42, 234-246, doi:10.1016/j.yjmcc.2006.08.018. 